\title{
QUE IMPORTÂNCIA TEM A DIMENSÃO ECONÔMICA PARA A PSICANÁLISE CONTEMPORÂNEA? UM ESTUDO APROFUNDADO SOBRE O OBJETO PRIMÁRIO E A AMBIVALÊNCIA DAS PULSÕES EM FREUD ${ }^{1}$
}

André De Martini Nelson Ernesto Coelho Junior

Resumo: No presente trabalho, através de um percurso pelos textos freudianos, iremos acompanhar os engendramentos entre sujeito e objeto que se dão pelos caminhos pulsionais, dentro de uma perspectiva econômica. Ora, o que nos interessa aqui é colocar em questão o que nos parece ser um certo enfraquecimento ou "desvitalização" da teoria, em que tanto a sexualidade como os elementos mais "crus" do psiquismo vão sendo deixados de lado em nome de uma pretensa ênfase dos aspectos relacionais. Interessa-nos, especificamente, pensar que papel pode ter a dimensão econômica (tal como formulada por Freud) nos debates psicanalíticos contemporâneos em que a ética é trazida para o primeiro plano. Parece-nos que a dimensão econômica ou pulsional em psicanálise, longe de ser avessa ao lugar do outro na constituição do psiquismo, pode trazer esclarecimentos únicos a esse respeito, evidencian-

1 Este artigo baseia-se na discussão do segundo capítulo da dissertação de mestrado de De Martini (2006), realizada com bolsa CNPq. 
do a sustentação mútua entre Eue Outro num campo compartilhado de instalação de subjetividades.

Palavras-chave: Freud (Sigmund). Psicanálise. Objeto primário. Pulsão. Ética.

\section{Introdução}

Uma das marcas distintivas da clínica, ao longo da história da psicanálise, tem sido o aumento da importância que se tem dado ao objetona constituição da subjetividade, e a passagem gradual do foco intrapsíquico para considerações acerca da subjetividade deste outro para quem sou um objeto ${ }^{2}$. As reflexões acerca da constituição ou instalação da subjetividade passaram a implicar o exame detido sobre as relações com o ambiente, ou com o outro, para além das condições constitucionais ou idiossincráticas do sujeito. As possibilidades clínicas diante dos casos de psicose, das patologias do vazio, do autismo ou dos casos borderlineestão estreitamente vinculadas aos desenvolvimentos que se fizeram no sentido de desvelar o papel do outro, do objeto, na gênese ou tratamento desses casos (o que se estende para a clínica psicanalítica de forma geral).

No presente trabalho, o leitor irá acompanhar um percurso que se restringe basicamente aos textos freudianos, e eventualmente poderá perguntar-se qual o alcance ou legitimidade disso, uma vez que, não sendo este um tema para Freud, o mais lógico seria buscá-lo nos autores ou debates contemporâneos (Baranger, 1994; Coelho Junior \& Figueiredo, 2004; Green, 1965, 2000; Simão, Souza, \& Coelho Junior, 2002). Ora, o que nos interessa aqui é colocar em questão o que nos parece ser um certo enfraquecimento ou "desvitalização" da teoria, em que tanto a sexualidade como os elementos mais "crus" do psiquismo vão sendo deixados de lado em nome de uma pretensa ênfase dos aspectos relacionais. Interessa-nos, especificamente, pensar que papel pode ter a dimensão econômica (tal como formulada por Freud) nos debates psicanalíticos contemporâneos em que a ética é trazida para o primeiro plano 3 .

2 Neste ponto, é pertinente fazer algumas discriminações terminológicas. Ao longo do texto utilizaremos o termo sujeito num sentido mais amplo, próximo ao uso freudiano. Neste contexto, objeto será tudo aquilo que a esse sujeito se reportar libidinalmente, conforme o sentido técnico que "objeto"tem para a psicanálise. Entretanto, sabemos que desde o final do séc. XIX, notadamente a partir das discussões acerca das "ciências do espírito", a problemática do sujeito vem sofrendo um deslocamento gradual (mas nunca absoluto) do campo epistemológico para os campos ontológico e ético. A psicanálise inaugura uma prática que, ao longo do tempo, também busca interlocuções nesses outros campos.

3 Ogden (2003) faz uma interessante proposição sobre a leitura de textos psicanalíticos, numa tensão entre os olhares contemporâneos e aqueles que supomos ter existido no passado. 
Ao propormos explorar, através de Freud, a dimensão econômica da psicanálise, temos em mente que será apenas na justa medida em que isso possa esclarecer pontos importantes em nossa discussão maior - por exemplo, com o conceito de ambivalência, mesmo que não seja de forma direta, iremos nos deparar com a figura do outro. No entanto, trata-se, neste momento, de um outro enquanto objeto correlato dos investimentos pulsionais para um determinado sujeito. É objeto para o sujeito, objeto da satisfação pulsional. De início, ao caracterizar a pulsão, Freud define o objeto enquanto seu atributo mais lábil. Mas gostaríamos de fazer o leitor notar que mesmo Freud, que descreve as pulsões na maioria das vezes enquanto um atributo do sujeito (parte de sua constituição), em outros momentos a apresenta como um campo intermediário entre sujeito e objeto.

Dessa forma, será crucial acompanhar de perto, e com algum cuidado, os engendramentos entre sujeito e objeto que se dão pelos caminhos pulsionais, dentro de uma perspectiva econômica. Os textos de Freud abordados aqui serão, principalmente, "Três ensaios sobre a teoria da sexualidade" (1905/1996a), "Os instintos e suas vicissitudes" (1915/1996c) e "O problema econômico do masoquismo" (1924/1996d), no que podem contribuir para uma discussão sobre a relação sujeito-objeto. Ao final desse percurso, parece-nos possível esperar como resultado a convicção de que as considerações atuais sobre ética e psicanálise não podem se ater exclusivamente aos fenômenos de identificação, das relações de objeto, ou mesmo daquilo que mais amplamente se chama intersubjetividade.

\section{O Surgimento, pela libido, do objeto enquanto entidade total}

Como podemos pensar a constituição do objeto, a partir de Freud? Ao descrever a constituição do sujeito na sexualidade, Freud considera o período de primado das pulsões parciais e autoeróticas, quando o próprio corpo é eleito como objeto de satisfação; ao chegar à puberdade, introduz-se então o outro enquanto objeto sexual total. Até a chegada desse momento, o objeto deveria contar para a pulsão apenas como um fator contingente, um "pretexto" para processos cujas considerações iniciam e terminam no sujeito. Mais propriamente, o outro ressurgirá como tal quando do primado genital, mas essa passagem permanece um tanto enigmática: Freud oferece apenas uma explanação de valor meramente descritivo, na qual o surgimento do objeto total é compreendido enquanto um efeito de propagação ou supervalorização a partir das pulsões parciais. De fato, precisamos procurar entender por que a genitalidade não poderia ser meramente mais uma satisfação parcial. 
Vejamos, a princípio, o que Freud diz sobre este efeito de propagação. Descreve um movimento como que de "entrega" do sujeito ao objeto, em que a meta ou finalidade ${ }^{4}$ valorizada espalha-se por todo o objeto. A libido, assim, teria a intenção de se "apoderar do objeto sexual em todos os sentidos", sendo a genitalidade um tipo especial de configuração sua, uma espécie de "porta de entrada" do objeto total, ao mesmo tempo em que arregimenta sob seu domínio as demais pulsões parciais.

Dessa forma, Freud aponta como explicação para o interesse sexual pelo objeto como um todo - e não só por sua genitália, que poderia muito bem ser apenas mais um objeto parcial, como sugerimos - um efeito de propagação, que se ancora na genitalidade. De qualquer modo, quer seja na consideração do fenômeno pelos seus resultados, quer seja na consideração de um aspecto específico da genitalidade, Freud introduz a questão do outro tomado em seu todo. Entretanto, mesmo com o reforço da ideia de "corrente colateral" (Freud, 1905/1996a, p. 142, nota 2), ou seja, a ideia de uma concomitância dos diferentes modos de satisfação libidinal, isso em si não garantiria ainda a consideração do outro como um objeto total, mas apenas, no máximo, um conglomerado de partes. Restaria a tarefa de desvelar como essa organização da pulsão a que chamamos genitalidade demanda considerar o outro em sua totalidade, como um alguém. E é nesse ponto que Freud introduz a questão do amor, que permanecerá como referência para o conjunto das relações pulsionais do sujeito com seu objeto. Em termos libidinais, o que constituiu primariamente este objekt? Partes, pelo visto, correlatas a pulsões que se colocam num continuum em direção à meta final (genital) e madura. Até aqui, numa leitura mais superficial, seria como se o objeto como um todo surgisse por mero efeito desenvolvimentista, resultando, como numa espécie de etapa ou estágio superior, na supervalorização libidinal.

Utilizando-se da problemática do fetiche (ainda no contexto dos "Três ensaios sobre a teoria da sexualidade"), Freud chama a atenção para um ponto de ligação entre a normalidade e o fetichismo, nesta supervalorização do objeto sexual em suas outras partes. No fetiche, um efeito de deslocamento do interesse libidinal aconteceria principalmente quando do impedimento da meta normal. Contudo, nesse caso, o que se observa é o caminho reverso da propagação - o objeto tomado em sua totalidade é substituído por uma parte sua. O que define a condição patológica do fetiche é o abandono da meta genital normal em nome do fetiche, e também quando este se desprende de uma pessoa e se torna o único objeto sexual. Nessa situação, observamos uma regressão da organização libidinal genital para um investimento fálico cujo resultado é a retirada de 
cena do objeto total. O fetiche resulta de um efeito de "supervalorização" do objeto que se propaga a tudo que diz respeito (associativamente) a ele, é uma parte que remete ao todo. É este "todo" do objeto que nos interessa, em sua gênese.

Há dois elementos que nos parecem fundamentais para melhor compreendermos o surgimento do objeto neste seu estatuto - um objeto total -, seguindo a argumentação freudiana. O primeiro consiste em considerarmos sua observação de que, quando da instauração do primado genital, parece que o que acontece é uma ação "anímica" que arregimenta todos aqueles processos até então mais somáticos (e ligados ao princípio do prazer). O segundo consiste em considerar que tanto o primado genital quanto o encontro do objeto total "já estão prefigurados na vida infantil" (Freud, 1905/1996a, p. 221). Podemos observar estes dois pontos na famosa passagem do texto de Freud:

\begin{abstract}
Ao mesmo tempo, consuma-se no lado psíquico o encontro do objeto para o qual o caminho fora preparado desde a mais tenra infância. Na época em que a mais primitiva satisfação sexual estava ainda vinculada à nutrição, a pulsão sexual tinha um objeto fora do corpo próprio, no seio materno. Só mais tarde vem a perdê-lo, talvez justamente na época em que a criança consegue formar para si uma representação global da pessoa a quem pertence o órgão que Ihe dispensava satisfação. Em geral, a pulsão sexual torna-se autoerótica, e só depois de superado o período de latência é que se restabelece a relação originária. Não é sem boas razões que, para a criança, a amamentação no seio materno torna-se modelar para todos os relacionamentos amorosos. $\mathrm{O}$ encontro do objeto é, na verdade, um reencontro. (Freud, 1905/1996a, p. 210)
\end{abstract}

Temos, com esses dois pontos, a abertura necessária para discutirmos os aspectos mais primitivos da constituição subjetiva apresentados até aqui: é que o objeto amoroso possui uma história, uma condição primária, mesmo antes de poder ser (re)conhecido plenamente. É preciso considerar que, de uma forma ou de outra, já há, desde o princípio, a ação deste outro considerado em si, enquanto uma figura total, e ainda que não possa ser reconhecido como tal pelo bebê nesses primórdios, deixa uma marca que permanece na vida psíquica enquanto uma prefiguração. Continuemos então com mais alguns passos nessa direção.

Voltemos ao tema do amor, que se liga à virada anímica responsável pelo surgimento do objeto total. Freud, ao tratar do amor, coloca-o em estreita correlação com a genitalidade - poderia ser tomado como a totalidade da corrente sexual:

O fato de não termos o hábito de dizer que um instinto sexual isolado ama o seu objeto, mas considerarmos a relação entre o ego e seu objeto sexual como o caso mais apropriado no qual empregar a palavra "amor" - esse fato nos ensina que a palavra só pode começar a ser aplicada nesse sentido após ter 
havido uma síntese de todos os instintos componentes da sexualidade sob a primazia dos órgãos genitais e a serviço da função reprodutora. (Freud, 1905/ 1996a, p. 142)

De repente, ao lado do fator propriamente genital passa a contar também esse tipo de vinculação especial entre um "ego total" e seus objetos - a que se chama amor -e isso adquire um caráter mais abrangente do que poderíamos supor em termos da satisfação do sujeito, exclusivamente. Quer dizer, partindo da dimensão mais econômica da relação sujeito-objeto, vemos que há a irrupção dessa problemática ligada à constituição de lugares subjetivos (de um Eu, de um Outro), que neste caso aparece como esta corrente de amor, que pode ser entendida como uma reverberação, na dimensão econômica, de questões acerca da alteridade, do outro tomado ele também enquanto um sujeito. Veremos no item seguinte como isso se imbrica ao tema da ambivalência.

E de modo similar ao que acontece com o amor, para Freud, o ódio também deve ser referido à situação global do sujeito com seus objetos. Além disso, a oposição amor/ódio só configurou-se assim indiretamente, pela mediação da oposição prazer/desprazer - ou seja, não é uma oposição originária. No ódio, não se trata simplesmente de uma pulsão, mas de uma repulsão (o que, eventualmente, significará um vínculo muito forte com o objeto). Amor e ódio, enfim, descrevem não exatamente atributos específicos da pulsão, mas as relações "entre o ego total e os objetos".

O ódio desempenha também um papel muito importante na gênese do objeto total, enquanto reação à situação de frustração, pois surge quando o objeto começa a tomar forma e aparecer enquanto tal ao Eu onipotente:"Quando, durante a fase do narcisismo primário, o objeto faz a sua aparição, o segundo oposto ao amar, a saber, o odiar, atinge seu desenvolvimento" (Freud, 1915/1996c, p. 141). Entretanto, a questão do ódio aqui ainda não está muito clara, pois se coloca também a questão do desligamento e da indiferença, num prenúncio da pulsão de morte:"A indiferença se enquadra como um caso especial de ódio ou desagrado, após ter aparecido inicialmente como sendo seu precursor."(p.141). Além disso, há que se considerar aquela situação de impossibilidade de o sujeito dispor de seu ódio sobre o objeto, por medo de destruí-lo.

Antes de passarmos ao ponto seguinte, façamos um breve adendo sobre a questão do narcisismo. Parece ser possível deduzirmos dois caminhos concomitantes para os processos de subjetivação que levam ao encontro com o objeto total, pois o narcisismo coloca nuances próprias a essa questão. Se o amor representa a totalidade dos investimentos que ligam o sujeito ao objeto, é preciso também levar em consideração o su- 
gestivo fato de haver dois tipos de amor - o de apoio e o narcísico -, o que nos leva a supor então duas qualidades distintas no encontro com o objeto total. A saída narcísica em direção ao objeto pode estar relacionada com o fato de que esse outro que é buscado, imagem e semelhança de si próprio, não obstante, está fora do próprio corpo. Essa saída do próprio corpo nos dá uma ideia do caráter da busca narcísica, o que a coloca numa posição bem distinta das pulsões no autoerotismo. A bem dizer, Freud mesmo enfatiza literalmente que há "dois caminhos para o encontro do objeto" (Freud, 1905/1996a, p. 210, nota 1), e podemos então pensar em duas vias distintas que se sobrepõem.

Especialmente na escolha amorosa de objeto por apoio, Freud chama a atenção para um tipo de vínculo em que o que conta é a relação de cuidado, nos moldes da relação do bebê com quem o amamenta; no entanto, para Freud, isso em momento algum exclui ou antepõe-se aos vínculos de satisfação libidinal. Às vezes, por exemplo com Winnicott, temse a impressão de haver na constituição psíquica dois momentos segmentados ou estanques, um ligado ao Eu e outro libidinal; mas, pelo que aqui vai sendo apresentado com Freud, fica difícil imaginar que esses dois aspectos da constituição do psiquismo não estejam influenciando-se mutuamente desde o início. É nesse sentido que Freud falará do "objeto sexual na fase de amamentação", ressaltando que:

O trato da criança com a pessoa que a assiste é, para ela, uma fonte incessante de excitação e satisfação sexuais vindas das zonas erógenas, ainda mais que essa pessoa - usualmente, a mãe - contempla a criança com os sentimentos derivados de sua própria vida sexual: ela a acaricia, beija e embala, e é perfeitamente claro que a trata como um substituto de um objeto sexual plenamente legítimo. (Freud, 1905/1996a, p. 210)

Ainda sobre esse caráter simultâneo da dimensão pulsional e "intersubjetiva", há nesse mesmo texto uma nota, acrescentada em 1910, muito clara e específica na qual Freud faz uma correção em relação ao modo como expôs, no texto sobre o pequeno Hans (Freud, 1909/1996b), o autoerotismo e o amor de objeto: "Tive ainda minha atenção chamada para uma falha na exposição feita no texto, que, em prol da clareza, descreveu a distinção conceitual entre as duas fases, de autoerotismo e de amor objetal, como se fosse também uma separação temporal." (Freud, 1905/1996a, p. 182). E, mais adiante, define a vida sexual infantil como "essencialmente" autoerótica, o que não raro é tomado como "exclusivamente". Dessa forma, é em momentos como esse que temos clareza do duplo papel do objeto. 


\section{O papel da ambivalência}

Vejamos agora o fenômeno dos pares sadismo-masoquismo e exibicionismo-voyeurismo. Esses parecem implicar o objeto como um todo mesmo antes do advento do objeto total, e de forma independente, no início, das pulsões parciais ligadas às áreas erógenas. O objeto passa a ser tomado em sua condição subjetiva de ser aquele que ocupa um destes papéis em relação ao sujeito:

Contudo, devemos admitir que também a vida sexual infantil, apesar da dominação preponderante das zonas erógenas, exibe componentes que desde o início envolvem outras pessoas como objetos sexuais. Dessa natureza são as pulsões do prazer de olhar e de exibir, bem como a de crueldade, que aparecem com certa independência das zonas erógenas e só mais tarde entram em relações estreitas com a vida genital, mas que já na infância se fazem notar como aspirações autônomas, inicialmente separadas da atividade sexual erógena. (Freud, 1905/1996a, p. 180)

Há aqui uma implicação direta do outro, para além de sua mera posição libidinal correlata às zonas erógenas. Fica difícil encontrar um lugar claro para isso no corpo teórico. A ligação a essa outra pessoa (enquanto um objeto total) através da genitalidade só ocorrerá mais tarde, mas Freud é bem claro quanto à sua importância desde o início, independentemente da dinâmica pulsional sexual propriamente dita. Poderíamos eventualmente supor que isso se liga às pulsões do âmbito do Eu (já que nessa época Freud as toma em conjunto com as sexuais), mas veremos adiante que tal suposição não é satisfatória. Talvez não se trate exatamente de um tipo de pulsão, mas de uma "natureza" especial de toda pulsão, que remeteria tanto ao Eu quanto ao Outro. Ao falar sobre a organização sádico-anal, Freud chama a atenção para a existência, já demonstrável aí, de um objeto alheio, ainda que falte sua subordinação à organização genital, quando então esse objeto será um objeto total. Isso se dá pela divisão de opostos ativo/passivo no sadismo, entre sujeito e objeto.

Outro ponto interessante nos engendramentos entre o Eu e o Outro pela pulsão está nas origens da curiosidade das crianças pelos genitais de outrem:

Entretanto, minhas investigações da meninice tanto de pessoas sadias quanto de doentes neuróticos forçam-me a concluir que a pulsão de ver pode surgir na criança como uma manifestação sexual espontânea. As crianças pequenas cuja atenção foi atraída, em algum momento, para sua própria genitália geralmente pela masturbação - costumam dar o passo adicional sem ajuda externa e desenvolver um vivo interesse pelos genitais de seus coleguinhas. (Freud, 1905/1996a, p. 181) 
Ou seja, as crianças pequenas colocam o outro no lugar de si, encaminhando para ele o interesse exploratório que era originariamente voltado para o próprio corpo. É interessante o movimento de tomar o próprio corpo como objeto de investigação - que inclusive se dá sobo olhar do outro - para depois querer ver o corpo do outro.

No texto sobre os destinos da pulsão, Freud retoma a questão e descreve o percurso do sadismo ao masoquismo, no qual "Uma pessoa estranha é mais uma vez procurada como objeto; essa pessoa, em consequência da alteração que ocorreu na finalidade instintual, tem de assumir o papel do sujeito." (Freud, 1915/1996c, p. 133). Nesse trecho, há uma nota em que Strachey tenta dissipar essa ambiguidade da frase, sugerindo que "sujeito", nesse caso, refere-se apenas ao lugar ativo a que passa essa pessoa estranha, e que esse "sujeito" não se confunde com o sujeito original nos seus demais aspectos. Ora, não é justamente essa possibilidade de uma certa confusão e dissipação de referenciais entre sujeito e objeto (justamente nos aspectos que definem alguém enquanto tal) que permite que um faça as vezes do outro? Note-se que não se trata da abolição completa dos limites entre um e outro:é preciso que haja dois, para que o interjogo sádico-masoquista seja possível. No entanto, esse outro estranho que o masoquista requisita não pode ser qualquerum, bastando que cumpra essa condição de "ativo" - tem de ser alguém com quem ele possa identificar-se. A satisfação, nesse caso, não é algo impessoal, há sempre um sujeito peculiar.

Um excesso de cautela quanto às confusões entre sujeito e objeto não permite, por exemplo, que compreendamos muito bem trechos como este:

e no sadismo a fonte orgânica, que é provavelmente o aparelho muscular com sua capacidade para a ação, aponta inequivocamente para outro objeto que não ele próprio, muito embora esse objeto seja parte do próprio corpo do sujeito. (Freud, 1915/1996c, p. 137)

A frase é (propositalmente?) ambígua: é uma parte do próprio corpo do sujeito que apresenta uma alteridade ou é um outro que tomo como se fosse parte do meu corpo? Em ambos os casos, as fronteiras entre sujeito e objeto estão esmaecidas.

Façamos então uma pequena apresentação das proposições de Freud, sobre a passagem do sadismo ao masoquismo:
(a) SUJ $\longrightarrow$ violência/poder $\rightarrow$ OBJ
(sadismo) - voz ativa
(b) SUJ $\longleftarrow$ violência/poder OBJ
(neurose obsessiva, p.e.) - voz reflexiva
(c) SUJ $\longleftarrow$ violência/poder $\longleftarrow$ OBJ
(masoquismo) - voz passiva

Figura 1. A passagem do sadismo ao masoquismo. 
Em (c), o objeto guarda semelhança com a situação original do sujeito, no sadismo.

Será no texto sobre os destinos da pulsão que encontraremos uma tentativa de dar um lugar teórico para essa dimensão da pulsão de que vimos falando até aqui; vejamos algumas passagens importantes antes de seguirmos na argumentação:

O fato de que, nesse período ulterior de desenvolvimento de um impulso instintual, seu oposto (passivo) possa ser observado ao lado dele merecer ser assinalado pelo termo bem adequado introduzido por Bleuler - "ambivalência". (Freud, 1915/1996c, p. 136)

E em ambos esses casos [isto é, na escopofilia passiva e no masoquismo] o sujeito narcisista é, através da identificação, substituído por outro ego, estranho. (Freud, 1915/1996c, p. 137)

Então, conforme o objeto ou o sujeito seja substituído por um estranho, o que resulta é a finalidade ativa de amar ou a passiva de ser amado - ficando a segunda perto do narcisismo. (Freud, 1915/1996c, p. 138)

Reconhecemos a fase de incorporação ou devoramento como sendo a primeira dessas finalidades [metas sexuais provisórias, antes do primado genital e do objeto e Eu totais] - um tipo de amor que é compatível com a abolição da existência separada do objeto e que, portanto, pode ser descrito como ambivalente. (Freud, 1915/1996c, p. 143, comentários nossos)

Acreditamos que o conceito de ambivalência pode colocar-se aqui como um operador da discussão sobre essa natureza especial de toda pulsão que, colocando-se aquém sujeito e objeto, é capaz de engendrálos nesse movimento constitutivo que ora nos interessa. A utilização mais banal do conceito, em termos da oposição amor-ódio, está presente também, mas como um caso particular disso que é um mecanismo complexo de inversões de posição, deslizamentos e oposições, que implicam as formas de amor parcial e total e as possibilidades correlatas de engendramento entre sujeito e objeto.

Antes do primado genital - quando ainda não podemos falar de um Eu plenamente constituído e objeto total - Freud comenta um tipo de amor primitivo, moldado pela meta ou finalidade oral (incorporação ou devoramento), no qual objeto e sujeito encontram-se numa relação de abolição da existência separada e que, "portanto, pode ser descrito como ambivalente.". A ambivalência, dessa forma, antes de ser equacionada com a ideia do conflito na relação amor-ódio, aponta para essa inversão dos lugares entre sujeito e objeto. Assim, a ambivalência aqui não se confunde com o uso mais comum de ambiguidade, tal como poderíamos 
considerar em autores como Melanie Klein ${ }^{5}$ (presença inata de quantidades de amor e ódio): antes, é a condição de reversibilidade da pulsão em seu oposto, pela capacidade do sujeito e do objeto trocarem de lugar, quando então a satisfação do outro, um objeto que também é um sujeito - um objeto-sujeito - faz as vezes de minha própria satisfação. Freud coloca esse como um dos "destinos das pulsões", junto com a repressão, o retorno ao Eu e a sublimação.

Na prática, o que acontece na situação de ambivalência, mais do que a alternância temporal entre uma e outra posição (ativo e passivo, sujeito e objeto), é a concomitância de momentos contraditórios, de posições simultâneas ${ }^{6}$. Mas já nos Três ensaios..., nos tópicos referentes ao olhar/exibir e ao sadismo/masoquismo, encontramos uma antecipação disso, pois Freud parecia particularmente impressionado pelo fato de as formas ativa e passiva dessas perversões serem geralmente encontradas na mesma pessoa: "Assim, vemos que algumas das inclinações à perversão apresentam-se singularmente como pares de opostos, o que, em conjunto com um material a ser posteriormente apresentado, pode reivindicar uma elevada significação teórica" (Freud, 1905/1996a, p. 151).

A característica de reversibilidade da pulsão encontra sentido na imperiosidade da necessidade de satisfação - ela deve ser atingida mesmo que para isso o sujeito tenha que deixar de ocupar seu lugar original e colocar-se no lugar de objeto. Isso, por sua vez, só é possível porque um dia o Eu já experimentou a si próprio enquanto objeto de investimento e satisfação, nos moldes do narcisismo. E é claro que podemos pensar também na contribuição que um investimento original, do objeto, permite em primeiro lugar que o Eu possa colocar-se nessa condição de objeto. Do ponto de vista da organização libidinal do sujeito, o que permite a inversão dos lugares de sujeito e objeto é esse movimento reflexivo proporcionado pela organização narcísica do Eu. É preciso resgatar no uso comum que fazemos do termo "identificação" essa característica que fica mais evidente quando falamos em "ambivalência", essa intrincada rede

5 "Klein distinguiu entre noção de ambivalência e de ambiguidade. Ambivalência: o sujeito faz, quanto a um mesmo ser, duas imagens alternativas, que não são percebidas como representativas do mesmo objeto. Ambiguidade: é uma noção da vida adulta. 0 sujeito percebe duas imagens, mas sabe que se referem ao mesmo objeto" (Merleau-Ponty, 1988/1990, p. 65). “a atitude característica da criança será uma atitude de ambivalência, duplo sentimento de onipotência e de impotência; a criança nada pode e tudo quer" (p. 115).

6 Laplanche e Pontalis (1993), em seu Fantasia Originária, Fantasia das Origens, Origens da Fantasia, ao comentarem os pares de termos sadismo/masoquismo e exibicionismo/voyeurismo, apontam que:"Aquém da forma ativa ou passiva da frase (ver-ser visto, por exemplo), seria necessário supor uma forma reflexa (ver-se a si mesmo), a qual, segundo Freud, seria primordial. Conviria, sem dúvida, apurar esse grau primordial lá onde o sujeito já não se situa nos diferentes termos da fantasia" (Nota 71, p. 98). 
de trocas e permutas entre sujeito e objeto, e também todo o jogo econômico de satisfação implicado nisso.

Para concluir esta parte, vejamos um esquema das três antíteses do amor propostas por Freud, procurando divisar aí esse movimento de inversões e anteposições entre sujeito e objeto, através do qual esses também se constituem. Essas antíteses abordam as relações de modo que as pulsões são tomadas em seu conjunto:
a) AMAR $\leftrightarrow \rightarrow$ ODIAR
ligada ao objeto
b) AMAR $\leftarrow \rightarrow$ SER AMADO
c) AMAR/ODIAR $\leftrightarrow \rightarrow$ DESINTERESSE \} em desligamento com o objeto

Figura 2. As três antíteses do amor.

a) Inversão do conteúdo em seu oposto: inverte-se não a posição ativa em passiva, mas sim a caracterização qualitativa da pulsão no seu todo; aqui mantêm-se os lugares do sujeito e do objeto. Parece que o mais importante na passagem de uma coisa a outra (de amar para odiar) é a manutenção da posição do sujeito da voz ativa. Daí, temos que a frustração e impossibilidade de realização do amar parece conjugar-se com um ressentimento ou ódio pelo objeto que frustra, de forma que o que é transformada é a própria caracterização da relação com o objeto no seu todo, qualitativamente.

b) Inversão ambivalente, propriamente falando, de ativo em passivo: a caracterização da relação (amor) parece ser mais importante do que o sujeito manter-se na voz ativa, de forma que se viabilizam o jogo identificatório e a satisfação por identificação, conforme vínhamos falando.

c) Inversão da própria possibilidade do investimento, ou catexia:Aqui há um vislumbre da pulsão de morte, da tendência regressiva da pulsão para seu estado mais extremado, em que se desiste ou se ataca qualquer possibilidade de ligação. Não há espaço para qualquer frustração.

É possível observar nesse esquema duas conotações (ou manejos) da pulsão de morte, que em si mesma impele o aspecto regressivo de toda pulsão. Desiste-se do objeto, podemos supor, quando o sujeito está numa condição mais integrada, e isso adquire uma conotação mais depressiva; ataca-se o objeto quando o sujeito está numa condição menos integrada, e isso adquire uma conotação mais paranoide, ou cindida. Tais considerações sobre a relação da ambivalência com a pulsão de morte, contudo, fogem dos propósitos do presente trabalho. 


\section{Ponderação sobre o papel do outro na determinação das pulsões, das zonas erógenas, seu lugar antes de ser consi- derado um objeto total}

Veremos a seguir como podemos pensar a constituição pulsional, tendo como pano de fundo os aspectos levantados nos tópicos anteriores: o surgimento do objeto total numa ligação libidinal privilegiada com o sujeito, a ideia de ambivalência como característica fundamental da própria dimensão pulsional e, por fim, o ódio e a indiferença no desligamento do objeto.

Na sua discussão a respeito das fontes da sexualidade, Freud destaca três grupos:

I) O primeiro relaciona-se com a reedição de um prazer já vivido em apoio a outros processos orgânicos;

II) O segundo dá-se pela estimulação das zonas erógenas - lembremos que o estabelecimento destas decorre por um processo particular em cada caso, muito associado às condições de cuidado básico e às pulsões parciais que surgem "apoiadas" no funcionamento natural de cada órgão. Sabemos também que a pulsão resulta de uma estimulação endossomática; dessa forma, devemos considerar que mesmo a estimulação apropriada, uma determinada "qualidade do estímulo" que se dá numa zona erógena, requer dois momentos, ou fatores:

a) Uma "história consolidada no corpo" (que leva em conta também as possibilidades fisiológicas), o que dá uma certa "autonomia de prazer" à região.

b) Um processo excitatório interno, sem o qual nenhuma pulsão seria possível. Qual o caráter disso que é interno? Trata-se aqui das disposições do sujeito, que dizem respeito tanto a sua constituição somática quanto à organização psiquíca em função do princípio do prazer.

III) Finalmente, o terceiro grupo está relacionado às pulsões mais misteriosas como a escopofílica (exibicionismo-voyeurismo) e a de crueldade (sadismo-masoquismo): ambas lidam, justamente, com a questão da ambivalência na constituição dos lugares do sujeito e do objeto.

Freud define a zona erógena, afinal, como toda a superfície da pele, em relação a "um certo tipo de estimulabilidade" (Freud, 1905/1996a, p. 190). Há aqui a proposição de uma diferenciação qualitativa na estimulação. Esse tipo de pensamento leva a crer que de fato a pulsão depende, para sua determinação, simultaneamente de elementos internos (constituição somática) e externos (qualidade de estimulação), ficando difícil tomar qualquer decisão exclusiva a respeito de se a pulsão é de natureza 
interna ou externa. Freud passa sem dificuldade de um nível quase biológico, organicista, para outro puramente psicológico, e vice-versa, sem que isso represente para ele qualquer problema. Em determinados momentos enfatizará mais um dos aspectos, mas nunca deixa de trazer ambos os lados para a discussão. Ora, a definição que Freud faz da pulsão a coloca em algum lugar entre o somático e o psíquico. Na primeira teoria das pulsões, dirá que "O que distingue as pulsões entre si e as dota de propriedades específicas é sua relação com suas fontes somáticas e seus alvos" (Freud, 1905/1996a, p. 172) - o objeto aqui conta como o fator mais contingente. Ao mesmo tempo, na caracterização da zona erógena, aponta para o fato de que há sempre um tipo específico de estimulação, que é na verdade o fator mais decisivo na experiência de prazer:"Assim, a qualidade do estímulo, mais do que a natureza das partes do corpo, é que tem a ver com a produção da sensação prazerosa" (Freud, 1905/1996a, p. 173). Isso remete ao papel do objetomãe no trato da criança, a partir da própria sexualidade daquela, e também ao papel do outro na ambivalência, o que se enquadra no terceiro grupo das fontes da sexualidade.

Como vimos, será também em termos qualitativos que Freud caracterizará a totalidade da corrente pulsional, pois com a genitalidade já se levará em conta o objeto tomado em si próprio e as trocas que podem se efetuar com ele. Mas deve ficar claro que são algumas atribuições da pulsão (objeto [objekt], finalidade ou meta [ziel, e fonte [quelle]) que variam qualitativamente, enquanto, em sua natureza mais "crua", no seu efeito de pressão [drang], não há uma dimensão de qualidades.

Vejamos a questão da passividade, desde esse ponto de vista. Uma "pulsão passiva" só o é em sua finalidade, de fato. Ao pensarmos no interjogo de pulsões que pode acontecer entre duas pessoas, chegamos à conclusão de que o que desperta a pulsão em alguém (considerando apenas o fator exógeno) é a qualidade de "estímulo" proveniente de outra pessoa, em função das próprias pulsões desta. Ao tomarmos os diferentes pontos de vista que se apresentam nessa situação entre dois sujeitos, a pulsão, de um modo geral, é simultaneamente ativa (vai de encontro ao objeto) e passiva (sedutora, provoca o movimento do objeto em direção a si, desperta a pulsão do outro).

Na passagem das relações parciais entre sujeito e objeto para o primado da genitalidade, há também uma questão relativa ao estatuto dessa passagem, como vimos anteriormente, de podermos compreendê-la num viés mais desenvolvimentista ou num mais estrutural. Nos Três ensaios..., Freud (1905/1996a) aponta que:

Cabe acrescentar, por último, que durante o período de transição da puberdade os processos de desenvolvimento somático e psíquico prosseguem por algum tempo sem ligação entre si, até que a irrupção de uma intensa moção 
anímica de amor, levando à inervação dos genitais, produz a unidade da função amorosa exigida pela normalidade. (p. 221)

É interessante notar aqui Freud sugerir que o fator responsável pela integração do primado genital é de natureza psicogênica, em contraponto a uma explicação mais biologizante e desenvolvimentista. Esse trecho corrobora o que vimos falando, da função que essa moção amorosa tem na passagem para a genitalidade, para o reconhecimento do objeto total. Entretanto, não é possível reduzir a pulsão à dimensão do psiquismo, perdendo de vista a origem orgânica da qual se faz representante, situando-se em algum lugar entre o orgânico e o psíquico.

Há um paradoxo também na temporalidade que implica os modos de satisfação da pulsão entre o período infantil e o adulto, com os respectivos papéis que o objeto em cada época deve cumprir. Refiro-me aqui ao aspecto ambíguo que está no par de termos "corrente de ternura" e "corrente sensual." O primeiro remete a este aspecto de cuidados com a criança (atendê-la em suas necessidades vitais, na constituição do Eu etc.); curiosamente, nesse período mais primitivo é a dimensão pré-genital das pulsões que domina a cena, quando então ela é, sob esse aspecto, uma pequena "perversa polimorfa". Freud fala da angústia da criança nesse momento, como um sinal da falta do objeto, principalmente na situação de insatisfação de "pulsões sexuais desmedidas", fazendo uma ligação direta entre a intensidade pulsional e os cuidados maternos. Já o segundo termo, da corrente sensual, indica a possibilidade de lidar com o objeto numa condição de maturidade sexual sob a égide do amor, mas que só pode cumprir seus desígnios a partir do resgate das pulsões parciais infantis, para compensar as inibições que se instalam na puberdade.

A natureza constitucional da pulsão, contudo, não pode ser tomada como um atributo absolutamente apropriado pelo sujeito, devendo antes ser considerada quase como um "estranho", que faz exigências, impulsiona, pressiona, é arredio, e cuja origem sempre nos escapa. Em última análise, podemos ver que a pulsão coloca-se igualmente aquém do sujeito, parecendo mesmo remontar mais a uma disposição biológica ou ao soma. Entretanto, como vimos, possui a curiosa característica de imbricar-se irremediavelmente aos processos psíquicos tão logo eles existam, o que a coloca na fronteira entre o somático e o psíquico. $O$ termo "econômico" denota bem esta característica duplamente fronteiriça da pulsão', de uma força que se define entre o somático e o psíquico, e entre sujeito e objeto: em Economia, temos sempre valores de troca, valores que fazem as vezes de objetos, medidas do potencial de trabalho, com-

7 Ver Green (1965). 
promissos entre partes etc. $O$ caráter quase exógeno da pulsão em relação aos domínios do sujeito ou do objeto parece funcionar como a "liga" entre os elementos que compõem a relação sujeito-objeto; nem lá nem cá, um pouco alheia a mim, um pouco alheia ao outro.

Teríamos de supor que, de fato, a pulsão seria tão somente um conceito que expressa as relações entre o soma e a psique, o soma seria tão somente a abstração do corpo sem o psiquismo, e a psique tão somente a abstração do corpo sem o registro orgânico.

Com isso que acabamos de ver, fica mais claro este caráter fronteiriço da pulsão em sua própria definição, o que reforça o argumento de que seu valor heurístico está justamente neste lugar paradoxal que ocupa entre sujeito e objeto, entre o somático e o psíquico, entre o biológico e o psicológico. A dificuldade de delimitação deste conceito, antes de ser motivo para embaraço, constitui a fonte mesma do que ele tem de mais valioso.

\section{A satisfação na genitalidade}

Destacando-se dos tipos de meta característicos das organizações anteriores, na genitalidade a finalidade vincula-se propriamente a um "objeto sexual alheio". Assim, introduz-se na dimensão da satisfação, do prazer, a importância do objeto total, do outro. É preciso atentar que, quando se fala do objeto total, devemos considerar aí o ponto de vista do sujeito que o busca, e não apenas do observador externo numa situação abstrata.

Com o que temos até aqui, fica claro que essa figura que contemporaneamente chamamos de outro assume também um lugar na questão econômica, pois é inserido na mediação da finalidade ou meta, na qual importa para o alívio da tensão sexual que, enquanto objeto, seja uma "representação global" de um outro. Agora é possível compreender melhor essa característica diferencial da organização genital, do ponto de vista econômico: uma nuance na economia pulsional em que a satisfação demanda um outro, (re)conhecido enquanto tal. Portanto, consiste numa perda e reducionismo quando leituras intersubjetivistas da psicanálise procuram livrar muito rapidamente a teoria da dimensão econômica, perdendo de vista nuances como as que vimos até aqui.

Há um aspecto curioso acerca da sexualidade infantil que serve para pensarmos essas questões numa situação mais concreta. A imaturidade sexual na criança (que caracteriza uma diferença com o desenvolvimento de outros aspectos) possui, para Freud, dois pontos de importante destaque: o sêmen e o orifício sexual feminino, que figuram como os principais enigmas da sexualidade infantil. O primado genital define-se no enigma infantil da emissão das células germinais, "a serviço da função 
reprodutora",e cuja finalidade exige um "objeto sexual alheio"Vemos nesse momento com Freud que o surgimento do outro é contingente a uma função do organismo, num ponto de vista mais biologizante. Mas mesmo nessa dimensão mais "crua" da sexualidade, na qual a questão é quase que exclusivamente pensada em termos organicistas, não haveria, a nosso ver, uma explicação suficiente da dimensão econômica presente aí, de forma que é preciso que nos perguntemos: qual a característica do alívio de tensão nesta situação particular, na passagem das metas das pulsões parciais à meta na organização genital?

Normalmente, a mera emissão das células germinais, por exemplo numa situação de masturbação solitária, traz um tipo de satisfação sexual muito inferior àquela proporcionada pelo ato a dois, fato que não pode ser explicado meramente por fatores fisiológicos. É Ferenczi que desenvolverá mais minuciosamente toda a nuance de identificações e misturas entre os parceiros na execução do ato sexual, colocando a dimensão mais "biológica" ou funcional em estreita relação com os aspectos mais imaginários (conforme o criativo Thalassa:Ferenczi, 1923/1993). Torna-se mais claro, com esse autor, qual a importância de se percorrer toda a montagem pré-genital no ato sexual, até se alcançar um estado propício para que o alívio da tensão ocorra de forma apropriada, quando então se atinge um certo grau de fusão entre os parceiros, condição necessária para que o homem possa desprender-se de uma parte de si - as células germinais - que também é, nesse momento, representante da totalidade de si próprio. A genitalidade adquire esse caráter arregimentador e finalista pelo efeito de extinção temporária da tensão libidinal, ao passo que os prazeres pré-genitais preliminares, concomitantemente à sua satisfação, provocam um aumento da tensão sexual (pré-prazer, em oposição a um prazer final). Freud fala desse aumento de tensão que cada satisfação parcial gera, por sua vez, até o alívio genital final; mas isso para ele é um enigma também, esse movimento paradoxal entre satisfação e estimulação, explicitado por Ferenczi com maior clareza.

É preciso que ocorra a identificação do sujeito com as células germinais, para que seja possível, de certa forma, o regresso às origens da vida - o útero materno. $O$ outro, na condição de objeto total para o sujeito, é então reencontrado, e veremos mais adiante porque isso se configura como um resgate de um momento originário mítico.

\section{Sobre esse outro primário, numa relação originária}

É chegado o momento de nos deter especialmente sobre esse "outro primário", que nos coloca a questão da consideração, com Freud, de algum outro fator além da organização libidinal na relação que a criança tem com o outro, nesse período de cuidados iniciais. Neste tópico, em 
particular, lançaremos mão de algumas ideias e desenvolvimentos que não se encontram no texto freudiano, mas que acreditamos poder nos remeter de volta a ele com maior esclarecimento - o objetivo, portanto, continua sendo o de explorarmos em profundidade isso que chamamos dimensão econômica da psicanálise.

Após a incursão pelo desenvolvimento das pulsões parciais, chegase ao momento de (re)encontro do objeto, que coincide com a saída do autoerotismo, pelo primado genital. Este se coloca numa classe diferente da organização das pulsões parciais que o antecedeu, pelo fato de arregimentá-las e redirecioná-las para fora, para outra pessoa. O fenômeno antes descrito, de supervalorização e propagação da valoração das partes para o todo, deixa de ocupar o papel principal na explicação do primado genital. Como vimos, esse encontro com o objeto já está, desde há muito tempo, agendado: é que a pulsão sexual, quando de seu apoio na pulsão de nutrição, conheceu esse objeto que não era seu corpo, e foi só na perda desse objeto que o autoerotismo entrou em cena, instaurando as pulsões parciais autônomas. Poderíamos nos colocar a questão de saber o que vem primeiro: se é a possibilidade de satisfação genital (dimensão econômica) que permite a vinculação a um objeto total (dimensão "intersubjetiva"), ou se é a possibilidade de encontro com um objeto total (dimensão "intersubjetiva") que permite o desenlace e retomada do jogo das pulsões parciais num primado de satisfação genital (dimensão econômica). Uma terceira possibilidade, que me parece a mais acertada, é a de que a saída genital (em seu caráter libidinal) e o encontro com o objeto são na verdade um só evento, e ambos relacionam-se à mesma raiz da constituição do sujeito. Nem só a pulsão nem só o outro constituem fatores suficientes para que aconteça esse reencontro do objeto, esse reconhecimento de um outro alheio a mim.

Mas consideremos ainda um pouco mais a questão, através da ideia de "tensão sexual."Mesmo no período de latência, ou antes, já há um certo efeito do primado genital adiantado, na medida em que o órgão sexual torna-se fonte de satisfação ("ainda sem finalidade"). Com essa ideia, Freud está descrevendo o processo de excitação sexual, que inclui o movimento aparentemente contraditório de satisfação $e$ aumento da tensão. De fato constitui um problema saber como, a partir de um prazer, de uma satisfação, surge um novo montante de tensão que, se não for atendido em uma nova finalidade ou meta, gerará desprazer. Quando o sujeito atinge a satisfação do prazer final, genital, momento em que o prazer é o mais intenso, não há mais esse aumento concomitante da tensão, de forma que é preciso explicar essa diferença de situações entre os tipos de satisfação. Freud começa com a hipótese de uma tensão fisiológica oriunda da substância sexual, que demandaria ser expelida. Mas tal explicação não dá conta das mulheres, da criança e dos castrados, de forma que deve haver outro fator mais fundamental. 
Há esse curso da excitação pelas pulsões parciais até atingir a pulsão propriamente genital, num movimento duplo de "satisfação sexual"e "excitação sexual" (alívio e aumento de tensão, respectivamente). Em outras palavras, a satisfação de cada pulsão parcial não chega a causar uma extinção eficaz do movimento libidinal como um todo, mas senão que aumenta e canaliza essa tensão em direção à satisfação genital - que, daí sim, leva à extinção temporária da libido. Um início para pensarmos esse problema está na seguinte questão: como poderíamos imaginar, apenas em termos da satisfação libidinal, que a criança pudesse abrir mão de um tipo de satisfação mais simples e imediato (no autoerotismo), em nome de um outro tipo muito mais trabalhoso? A saída de uma satisfação que já está garantida só faz sentido frente a:

a) uma impossibilidade desse tipo de satisfação dar conta da tensão que é criada concomitantemente, como se essa última tivesse uma demanda desde o início que só poderá ser satisfeita no encontro com o objeto total;

b) uma satisfação maior (em intensidade) ou mais completa (cuja finalidade é mais apropriada, conforme a situação a). De fato, essa possibilidade é complementar à primeira.

Retornemos àquele momento originário, o primeiro contato com o objeto, que Freud chama de "relação originária"; ainda é necessário que compreendamos como se instala o autoerotismo. A organização autoerótica não é anterior ao contato com um objeto alheio, senão que é justamente uma renúncia a esse, em troca de um objeto situado no próprio corpo. Freud irá relacionar essa perda do objeto primário ao reconhecimento da representação do todo deste outro - a mãe (Freud, 1905/1996a, p. 210). Ou seja, frente às demandas do bebê nesse início, aquele seio aparece, a partir de um determinado momento, como uma alteridade que impede a satisfação onipotente. A partir desse momento, a satisfação, de um modo geral, passa a estar ligada a impulsos parciais, que não necessitam da conivência ou permissão desse outro. É como se o self do bebê não tivesse ainda segurança suficiente para buscar satisfação noutro lugar que esse campo indiscriminado a partir de si mesmo, onde não há limitações, não há barreiras entre um e outro, entre sujeito e objeto - aqui não há trocas, do ponto de vista do bebê, mas apenas criação. A mãe, desse ponto de vista, terá sempre um caráter traumático, invasivo. Assim, no exato momento em que esse outro primário mostra-se enquanto um outro (por exemplo, numa situação de frustração particularmente intensa), imediatamente perde o seu estatuto, pois não há ainda condições de o bebê reconhecê-lo enquanto tal - e é a partir de então que se inicia o autoerotismo. $\mathrm{O}$ binômio familiar-estrangeiro é algo que provavelmente conhecemos antes do binômio Eu/não Eu. 
Então, melhor dizendo, talvez nesse momento mítico do primeiro contato com um objeto alheio, teríamos o conhecimento de uma região para além do si próprio, uma região não si, o que é coisa diferente da região de um objeto, reconhecido enquanto tal:"Para o ego do prazer, o mundo externo está dividido numa parte que é agradável, que ele incorporou a si mesmo, e num remanescente que Ihe é estranho" (Freud, 1915/ 1996 c, p. 141, itálicos nossos). Se essa explicação é correta, corroboram-se as ideias kleinianas de um Eu primitivo e dos mecanismos de projeção precoce. Pois, no início, não haveria ainda o reconhecimento de um outro enquanto alguém, mas sim enquanto uma região desconhecida, cujo controle e satisfação são incertos.

Mais freudianamente, é a "representação global da pessoa a quem pertence o órgão que lhe dispensava satisfação" que é responsável pela perda desse objeto primário. Ou seja, essa relação de pertença parece ser o fator que abala o status da representação do objeto que o bebê deseja (um objeto pleno de satisfação que pertence a ele): o bebê percebe, assim, que esse objeto primário não pode ser o objeto de pura satisfação porque possui uma dimensão que escapa ao seu desejo, uma dimensão talvez um pouco perigosa, porque incerta, onde as coisas não correspondem exatamente ao esperado, e que ameaça essa "potência criativa" que caracteriza a situação de onipotência. Além disso, talvez essa seja a primeira semente de uma relação entre parte ("órgão de satisfação") e todo ("representação global" de quem possui aquele órgão), uma relação metonímica que marcará presença de modo crucial nas situações mais tardias da castração (do fetiche etc.) e do narcisismo. Parece que a origem dos processos metonímicos no psiquismo tem seu início justamente aí, no desconhecimento do outro e de sicada qual uma totalidade, na tomada de partes, e no choque do reconhecimento da relação de pertença entre um e outro, quando então o caráter "total" daquela parte perde-se e redimensiona-se num outro nível. A instalação da organização de pulsões parciais é o que dá tempo ao psiquismo para que ele possa consolidar-se melhor nas suas capacidades de tolerar a frustração, e possa então reencontraro objeto total.

Agora nos encontramos mais bem posicionados para entender como é que se dá essa passagem da organização parcial para a total, e qual o papel do amor, da totalidade da libido: é só porque há uma marca desse contato com o objeto primário que foi renegado, que podemos pensar então numa direção do amadurecimento psíquico rumo ao primado genital. Esse amadurecimento não seria um desenvolvimento linear, mas sim um retorno, um reencontro, tal como Freud sugere. Esse objeto primário estaria de fato perdido, mas não o impacto da experiência com ele - por isso que, mesmo do ponto de vista estritamente econômico, podemos supor um motivo para a insuficiência da satisfação parcial, pois essa marca deixada pelo objeto primário demandará a futura 
finalidade ou meta genital, ligada a um objeto total, a um outro. Que fique claro, também, que esse objeto total da satisfação genital não é, e nem nunca poderá ser, aquele objeto primário, pois o sujeito também não pode nunca mais ser aquele "sujeito originário" (no texto "Os Instintos e suas Vicissitudes", p. 139, Freud, e também Strachey, mencionam numa nota a existência desse contato primordial com um "agente externo",e de um "ego da realidade original"). Assim, na ocasião do "ego da realidade original", há um contato imediato e direto com o mundo externo, mas seu estatuto é completamente indiferente para o bebê, que provavelmente vive num estado de indiscriminação entre o que seja um sujeito, ele próprio, e um outro. Com o "ego do prazer" é que então o mundo externo pode ganhar uma conotação de ser algo ruim, para onde projeta, ou de ser algo bom, que depois traz para si. Essa disparidade entre o objeto primário e o objeto total reencontrado, juntamente com a dimensão biológica da pulsão, parece ser o motivo da insuperável defasagem da satisfação em relação ao desejo. $O$ reencontro do objeto, portanto, significa também o encontro de uma finalidade inédita, mas cuja exigência é das mais antigas.

\section{Considerações finais}

Ao longo deste artigo, esperamos que tenha ficado claro, a partir de Freud, o papel e importância do eixo econômico da psicanálise, no que conte para a compreensão da relação Eu-Outro. Cremos que isso se coloca como uma crítica a uma certa tendência, em algumas leituras ditas intersubjetivistas, de ignorar os aspectos econômicos ou pulsionais da teoria e da prática clínica. É claro, procuramos nos ater aos aspectos que envolvessem a relação sujeito-objeto, sem qualquer pretensão de uma leitura sistemática da questão econômica como um todo (as questões das defesas, ou dos sintomas, por exemplo, foram deixadas de lado). A partir da pesquisa da complexa relação entre sujeito e objeto, esta dimensão pulsional coloca-se como um campo de vinculação absolutamente essencial para a compreensão dessa relação, e isso não é desconsiderar que existem aspectos que estão para além dessa dimensão.

A partir do conceito de ambivalência, vemos como este outro (que, embora também um sujeito, presta-se igualmente a ser objeto), vai abrindo à força um "oco" na teoria, criando ambiguidades, paradoxos e rachaduras. Vimos como o surgimento deste "outro total", considerado em seu próprio papel e importância, constitui uma passagem problemática para Freud.

Para finalizar, apontaremos brevemente dois aspectos presentes no texto O problema econômico do masoquismo (Freud, 1924/1996d), que 
dizem respeito à compreensão da metapsicologia, e que nos ajudam na melhor apreciação da dimensão econômica, tal como apresentado ao longo deste artigo.

Nesse texto, Freud retoma sua exposição do masoquismo feita nos Três ensaios..., incluindo uma dimensão de qualidades para além da questão quantitativa do princípio do prazer:"O prazer e o desprazer, portanto, não podem ser [tão somente] referidos a um aumento ou diminuição de uma quantidade (que descrevemos como "tensão devida a estímulo"), embora obviamente muito tenham a ver com esse fator." (Freud, 1924/1996d, p. 178). A explicação, mais adiante, está na suposição de que "o ritmo, a sequência temporal de mudanças, elevações e quedas na quantidade de estímulo" encontrariam seu lugar aí, enquanto fatores qualitativos.

Ora, para Freud, a finalidade equaciona-se à satisfação e, em última instância, remete a esse outro alheio ao sujeito, pela via da genitalidade. Toda a miríade de ações que levam a isso são finalidades ou metas intermediárias. Assim, em ambas as montagens da pulsão (pré-genital e genital), é preciso considerar o papel do objeto na constituição do psiquismo: à meta ou finalidade, poderíamos conjugar o entrelaçamento ou papel do objeto; à fonte, conjugar a qualidade de um estímulo; à pressão, conjugar o caráter obsidiante ou traumático do objeto. De fato, tais conjugações estão presentes no texto apenas de modo indireto, e não chegam a ocupar um lugar na formalização metapsicológica acerca da pulsão.

Vejamos agora o segundo aspecto. O narcisismo primário descortina-se numa condição muito especial de indiscriminação entre as libidos de objeto e narcísica, o que resulta, é verdade, num autocentramento narcísico do sujeito. Entretanto, como vimos, isso de modo algum pode obliterar a presença do objeto nesse período inicial de constituição da subjetividade - ainda que sujeito e objeto não possam ser discriminados, o fato é que ambos estão presentes e vivem uma situação de "amor verdadeiro". O objeto é necessário ao narcisismo primário, ainda que ainda não possa contar como um objeto total.

A eventual transformação de amor narcísico em objetal só acontece por mediação de processos que encontram sua base nessa situação primária de indiscriminação entre dois tipos de libido. As situações posteriores de encontro com o objeto total e da escolha de objeto amorosa (quando então os investimentos libidinais do próprio objeto passam a ser considerados como tais pelo sujeito) trazem a marca desse período inicial ambivalente, que é o campo onde se dão as identificações e os entrelaces edípicos.

Com isso, podemos concluir que o movimento pulsional libidinal, a partir da perda da relação originária com o objeto primário, consiste numa primeira divisão do psiquismo em duas correntes mentais: por um lado, o 
autoerotismo, enquanto uma operação de "deflexão" da pulsão para o próprio corpo; por outro, o narcisismo primário, que agora persiste com a marca da recusa desse mesmo evento, mas que sucede na manutenção da situação de "amor feliz", de indistinção entre investimentos no objeto e no próprio sujeito. Dessa forma, o reencontro com o objeto totalpode ser considerado como um novo período de convergência dessas correntes, agora já em condições de comportar a dimensão de alteridade desse objeto que se apresenta. Nesse momento a totalidade das pulsões é novamente "defletida", mas agora para fora, numa "intensa moção anímica de amor" (Freud, 1905/1996a, p. 221) que arregimenta a totalidade das pulsões parciais sob o primado genital.

Parece-nos que a dimensão econômica ou pulsional em psicanálise, longe de ser avessa ao lugar do outro na constituição do psiquismo, pode trazer esclarecimentos únicos a esse respeito, evidenciando os embates, dissonâncias, disparidades, e também a sustentação mútua e engendramentos entre Eu e Outro em um campo compartilhado de instalação de subjetividades.

Por fim, daremos por concluídos nossos objetivos se tivermos conseguido demonstrar ao leitor que os debates contemporâneos sobre intersubjetividade, ou sobre o papel do objeto na constituição do psiquismo, podem ser imensamente enriquecidos pelo esclarecimento dos primitivos enredamentos pulsionais entre sujeito e objeto. $O$ percurso que pudemos realizar nos textos de Freud nos levou a desvelar uma situação ambivalente de base na constituição das subjetividades, num enlace intrapsíquico que se mostra irremediavelmente marcado pela presença do outro.

How important is the economic dimension to contemporary psychoanalysis? A detailed study on the primary object and the ambivalence of the instinct in Freud

Abstract: Through the examination of Freudian texts, this paper focuses on the interplay between subject and object in relation to the instinct drives, from an economic perspective. The paper raises questions about what seems to be a weakening or "devitalization" of the theory. We believe that both sexuality and the "raw" aspects of the psyche are being left out by some trends within contemporary psychoanalysis, in the name of an alleged emphasis on the relational aspects. We are specifically interested in the role the economic dimension (as formulated by Freud) may have in contemporary psychoanalytic debates, in which ethics is brought to the foreground. Far from being averse to the otherin the constitution of the psyche, it is our understanding that the economic dimension can shed light on the subject. It 
highlights the mutual support between the Ego and the other, in the shared field where processes of subjectivation occur.

Keywords: Freud (Sigmund). Psychoanalysis. Primary object. Instinct. Ethics.

Quelle est l'importance de la dimension économique pour la psychanalyse contemporaine? Une étude détaillée sur l'objet primaire et l'ambivalence des pulsions chez Freud

Résumé: Dans cet article, dans un parcours à travers des textes freudiens, nous allons suivre de près, et avec une certaine prudence, les croisements entre sujet et objet qui arrivent dans les chemins de la pulsion, à partir d'une perspective économique. Ce qui nous intéresse ici c'est de mettre en question ce qui semble être un certain affaiblissement ou une « dévitalisation » de la théorie, dans lequel à la fois la sexualité et les éléments les plus « brutes » de la psyché sont abandonnés au nom d'un accent présumé sur les aspects relationnels. Il semble que la dimension économique ou de la pulsion dans la psychanalyse, loin d'oublier la place de l'autre dans la constitution de la psyché, peut éclaircir ce sujet, mettant en évidence les conflits, des désaccords, des différences, et aussi de l'appui mutuel entre les croisements du Je et de l'Autre sur le terrain partagé de placement des subjectivités.

Mots-clés: Freud (Sigmund). Psychanalyse. Objet primaire. Pulsion. Éthique.

¿Qué importancia tiene la dimensión económica para el psicoanálisis contemporáneo? Un estudio detallado sobre el objeto primario y la ambivalencia de las pulsiones en Freud

Resumen: En este trabajo, a través de un recorrido por los textos freudianos, vamos a seguir de cerca y con un cierto cuidado los engendramientos entre sujeto y objeto que se producen por los caminos pulsionales, dentro de una perspectiva económica. Así que lo que nos interesa aquí es poner en cuestión lo que nos parece un cierto debilitamiento, o una "desvitalización" de la teoría, en que tanto la sexualidad como los elementos "crudos" de la psique se están quedando en el olvido en nombre de una supuesta énfasis de los aspectos relacionales. Nos parece que la dimensión económica o pulsional en el psicoanálisis, lejos de ser contrario al lugar del otro en la constitución de la psique, puede traer esclarecimientos únicos a ese respecto, desta- 
cando los conflictos, disonancias, disparidades y también el apoyo mutuo y engendramientos entre el Yo y el Otro, en un campo compartido de instalación de subjetividades.

Palabras clave: Freud (Sigmund). Psicoanálisis. Objeto primario. Pulsión. Ética.

\section{Referências}

Baranger,W.(1994). Contribuições ao conceito de objeto em psicanálise. São Paulo: Casa do Psicólogo.

Coelho Junior, N. E., \& Figueiredo, L. C. (2004). Figuras da intersubjetividade. Interações, 9(17), 9-28.

De Martini, A. (2006). A metapsicologia dos descentramentos entre sujeito e objeto na obra de freud. Dissertação de mestrado, Instituto de Psicologia, Universidade de São Paulo, São Paulo.

Ferenczi, S. (1993). Thalassa, ensaio sobre a teoria da genitalidade. In Obras completas:psicanálise III. São Paulo: Martins Fontes. (Trabalho original publicado em 1923)

Freud, S. (1996a). Três ensaios sobre a teoria da sexualidade. In Obras completas (Vol. 7, pp. 123-212). Rio de Janeiro: Imago. (Trabalho original publicado em 1905)

Freud, S. (1996b). Análise de uma fobia em um menino de cinco anos. In Obras completas (Vol. 10, pp. 13-136). Rio de Janeiro: Imago. (Trabalho original publicado em 1909)

Freud, S. (1996c). Os instintos e suas vicissitudes. In Obras completas (Vol. 14, pp. 117-146). Rio de Janeiro: Imago. (Trabalho original publicado em 1915)

Freud, S. (1996d). O problema econômico do masoquismo. In Obras completas (Vol. 19, pp. 175-190). Rio de Janeiro: Imago. (Trabalho original publicado em 1924)

Green, A. (1965). Thirdness and psychoanalytic concepts. The Psychoanalytic Quarterly, 73, 99-135.

Green, A. (2000). The intrapsychic and intersubjective in psychoanalysis. The Psychoanalytic Quarterly, 69(1), 1-39. 
Laplanche, J., \& Pontalis, J.-B. (1993). Fantasia originária, fantasia das origens, origens da fantasia. Rio de Janeiro: Jorge Zahar.

Merleau-Ponty, M. (1990). Merleau-Ponty na Sorbonne: resumo de cursos: 1949 1952: psicossociologia e filosofia. São Paulo: Papirus.

Ogden, T. (2003). What's true and whose idea was it? International Journal of Psychoanalisys, 84(3), 593-606.

Simão, L. M., Souza, M. T. C. C., \& Coelho Junior, N. E. (2002). Noção de objeto, concepção de sujeito: Freud, Piaget e Boesch. São Paulo: Casa do Psicólogo. 
André De Martini, doutorando do Departamento de Psicologia Experimental do Instituto de Psicologia da Universidade de São Paulo. Endereço para correspondência: Av. Prof. Mello de Moraes, 1721 Bloco A, E-9. Cidade Universitária. CEP 05508-900. São Paulo, SP, Brasil. Endereço eletrônico: martini.de@gmail.com

Nelson Ernesto Coelho Junior, professor doutor do Departamento de Psicologia Experimental do Instituto de Psicologia da Universidade de São Paulo. Endereço para correspondência: Av. Prof. Mello de Moraes, 1721 Bloco A, E-9. Cidade Universitária. CEP 05508-900. São Paulo, SP, Brasil. Endereço eletrônico: ncoelho@usp.br

Recebido: $13 / 06 / 2011$

Aceito: 10/12/2011 